OPEN ACCESS

Edited by:

Franz Rödel,

University Hospital Frankfurt, Germany

Reviewed by:

Rachel Evans,

King's College London,

United Kingdom

Yishan Ye,

Zhejiang University, China

*Correspondence:

Zhao-Hui Tang

tangzh@tjh.tjmu.edu.cn

Specialty section:

This article was submitted to

Cancer Immunity

and Immunotherapy,

a section of the journal

Frontiers in Immunology

Received: 26 July 2021 Accepted: 15 November 2021 Published: 02 December 2021

Citation:

Chen D, Tang $T-X$, Deng $H$, Yang $X-P$ and Tang $Z-H$ (2021) Interleukin-7 Biology and Its Effects on Immune Cells: Mediator of Generation, Differentiation, Survival, and Homeostasis.

Front. Immunol. 12:747324. doi: 10.3389/fimmu.2021.747324

\section{Interleukin-7 Biology and Its Effects on Immune Cells: Mediator of Generation, Differentiation, Survival, and Homeostasis}

\author{
Deng Chen ${ }^{1}$, Ting-Xuan Tang ${ }^{2}$, Hai Deng ${ }^{1}$, Xiang-Ping Yang ${ }^{3}$ and Zhao-Hui Tang ${ }^{1 *}$ \\ 1 Division of Trauma and Surgical Critical Care, Department of Surgery, Tongji Hospital, Tongji Medical College, Huazhong \\ University of Science and Technology, Wuhan, China, ${ }^{2}$ Class 1901, School of Medicine, Wuhan University of Science and \\ Technology, Wuhan, China, ${ }^{3}$ Department of Immunology, Tongji Medical College, Huazhong University of Science and \\ Technology, Wuhan, China
}

Interleukin-7 (IL-7), a molecule known for its growth-promoting effects on progenitors of B cells, remains one of the most extensively studied cytokines. It plays a vital role in health maintenance and disease prevention, and the congenital deficiency of IL-7 signaling leads to profound immunodeficiency. IL-7 contributes to host defense by regulating the development and homeostasis of immune cells, including $T$ lymphocytes, B lymphocytes, and natural killer (NK) cells. Clinical trials of recombinant IL-7 have demonstrated safety and potent immune reconstitution effects. In this article, we discuss IL-7 and its functions in immune cell development, drawing on a substantial body of knowledge regarding the biology of IL-7. We aim to answer some remaining questions about $\mathrm{IL}-7$, providing insights essential for designing new strategies of immune intervention.

Keywords: IL-7, immune cells, generation, differentiation, survival, homeostasis

\section{INTRODUCTION}

Interleukin-7 (IL-7) was discovered in the last century and noted for its growth-promoting effects on progenitors of B cells in vivo (1). It was subsequently shown that IL-7 is a $25-\mathrm{kDa}$ soluble globular protein. IL-7 is produced by cells, such as fetal liver cells, stromal cells in the bone marrow (BM), and thymus and other epithelial cells, including keratinocytes and enterocytes (2). IL-7R is a heterodimeric complex consisting of the $\alpha$-chain (CD127) and the common cytokine receptor $\gamma$ chain, shared with the receptors for IL-2, IL-4, IL-7, IL-9, IL-15, and IL-21, and expressed in a variety of cells (3). Thus, IL-7 has multiple biological activities and influences various cell types through binding to its receptor. Deficiencies in IL-7 or IL-7R can lead to severely impaired immune cell development (Table 1). In the ensuing decades, the discovery of relevant signaling pathways was accompanied by recognition that IL-7 plays an indispensable role in the development and maintenance of many other immune cells. The vital regulatory functions of IL-7 throughout the entire immune system have become increasingly evident. 
TABLE 1 | The effects of deficiency of IL-7 and its receptor on development of immune cells.

\begin{tabular}{|c|c|c|}
\hline Cells & Effects & Treatment with IL-7 \\
\hline \multirow[t]{2}{*}{ Thymus } & Decrease in thymic cell count & Increase in thymic cell count \\
\hline & Thymic involution & Recovery of thymic function \\
\hline \multirow[t]{6}{*}{ T cells } & Inhibition of glucose metabolism & Restoring T-cell numbers \\
\hline & Cell atrophy & Increasing the diversity of $T$ cells \\
\hline & Impairment of $\mathrm{T}$-cell functions & Boosting $\mathrm{T}$-cell function \\
\hline & Severe impairment of $\mathrm{T}$ Iymphopoiesis & Inhibiting T-cell apoptosis \\
\hline & T-cell apoptosis & Promoting glucose metabolism \\
\hline & & Preventing T-cell from atrophy \\
\hline \multirow[t]{4}{*}{ B cells } & Block in transition to pro-B cells in the BM & Increase in B-cell numbers \\
\hline & Impairment of B differentiation potential & Allowing the transition of pro-B cells \\
\hline & Impairment of early B lymphopoiesis & Promoting B-cell survival \\
\hline & B-cell apoptosis & Increasing antibody production \\
\hline \multirow[t]{3}{*}{ NK cells } & Decrease in CD56 ${ }^{\text {bright }} \mathrm{NK}$ cell count & Increase in NK cell count \\
\hline & Impairment of functional responsiveness & Promoting survival of CD56 ${ }^{\text {bright }} \mathrm{NK}$ cells \\
\hline & Pronounced reduce of NK cell cytotoxicity & Inducing pronounced enhancement of NK cell cytotoxicity \\
\hline \multirow[t]{2}{*}{ ILCs } & Impairment of ILC differentiation and generation & Increase in ILC numbers \\
\hline & & Achieving the entry of lymphocytes into lymph nodes \\
\hline \multirow[t]{5}{*}{ Monocytes/macrophages } & Inhibition of monocyte activity & Increasing antigen presentation \\
\hline & Reduce of cytokine secretion & Augmenting the activity of monocytes \\
\hline & & Promoting cellular proliferation \\
\hline & & Increasing cytokine secretion \\
\hline & & Inducing the recruitment of monocytes \\
\hline \multirow[t]{2}{*}{ Dendritic cells } & Decrease in DC count & Continuous generation of functional dendritic cells \\
\hline & & Creating microenvironments for thymic DCs \\
\hline \multirow[t]{2}{*}{ Neutrophils } & Decrease in cell count & Increase in neutrophil count \\
\hline & Recruitment delay of neutrophils & Accelerating the recruitment of neutrophils \\
\hline \multirow[t]{2}{*}{ Eosinophils } & Reduced production of eosinophils & Increase in eosinophil numbers Promoting the survival of eosinophils \\
\hline & Inhibition of eosinophil survival & \\
\hline
\end{tabular}

\section{IL-7-Mediated Signaling Pathways}

IL-7R $\alpha$ is expressed in early thymocytes, T cells, pre-B cells, BM macrophages, and other immune cells. In these cells, IL-7 -mediated signaling initiates downstream signaling pathways through Janus kinase 1 (JAK1), JAK3, and phosphoinositide 3 -kinase (PI3K), which further leads to the activation and phosphorylation of signal transducer and activator of transcription 5 (STAT5). Phosphorylation of the IL-7R $\alpha$ chain is critical for the next stage of signal transduction because it contributes to the recruitment of STAT proteins. Phosphorylation of STAT proteins makes it possible for them to dimerize and translocate to the nucleus, where they act as transcription factors for target genes by binding to specific promoter elements. This results in changes in the expression of B-cell lymphoma 2 (Bcl-2) family members, such as increased expression of the anti-apoptotic molecules Bcl-xl, Mcl-1, and Bcl -2 and decreased expression of the pro-apoptotic molecules Bax, Bim, and Bad.

Src family kinases are also activated by IL-7 binding. These kinases play an important role in developing $B$ cells, but their function in IL-7 signaling has not been fully elucidated. Studies revealed that a potential function of Src kinases is to help activate STAT proteins because they can be phosphorylated by Src kinases independently or in conjunction with JAK proteins (4). One key downstream mediator of PI3K signaling is the serine/ threonine kinase Akt (PKB). Akt serves as a central modulator of normal and aberrant B-cell differentiation via regulation of variety of pro- and anti-apoptotic factors (5). The molecular structure and signal transduction pathways of IL-7R are shown in Figure 1.

Beyond contribution to homeostasis of peripheral $\mathrm{T}$ cells, elevated production of IL-7 promotes survival of both naïve and memory T cells (6). IL-7 was suggested to be involved in multiple stages of the development of B-cell progenitor, including its commitment, survival, differentiation, and proliferation (7). Moreover, IL-7 is a non-redundant cytokine with the ability to regulate the recruitment of leukocytes such as neutrophils and monocytes $(8,9)$. The results of animal experiments and clinical findings suggest that IL-7 is required to maintain and develop immune cells. In this review, we discuss IL-7 and its functions in immune cell development based on the body of knowledge regarding IL-7 biology (Figure 2), with the aim of answering the remaining questions, essential for the design of new immune intervention strategies.

\section{IL-7/IL-7R AND T CELLS}

Although IL-7 originally was discovered for a novel molecule acting exclusively on B cells, many critical biological activities of $\mathrm{T}$ cells are susceptible to IL-7.

\section{IL-7/IL-7R and T-Cell Lymphopoiesis}

IL-7 signaling is necessary for the development of T cells. Defects in IL-7 or IL-7 receptors in humans lead to severe impairment of $\mathrm{T}$ lymphopoiesis (10). IL-7 plays a unique role in the 


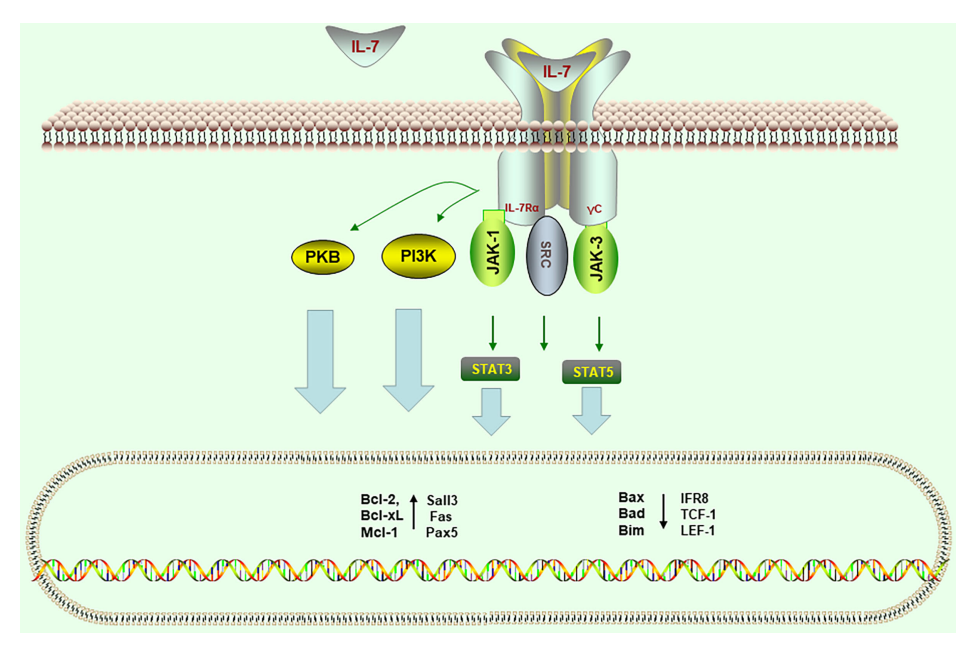

FIGURE 1 | Signal transduction pathways of interleukin-7 receptor (IL-7R). Downstream signaling pathways induced by IL-7 involve Janus kinase 1 (Jak1), Jak3 (through the g-chain), Src kinases, phosphatidylinositol-3 kinase (PI3K), phosphokinase B (PKB), STAT3 (signal transducer and activator of transcription 3), and STAT5. Signal transduction induces changes of gene expression levels in the nucleus, including promoting anti-apoptotic factors (such as Bcl-2, Bcl-xL, and Mcl-1) and inhibition of pro-apoptotic factors (such as Bax, Bad, and Bim).

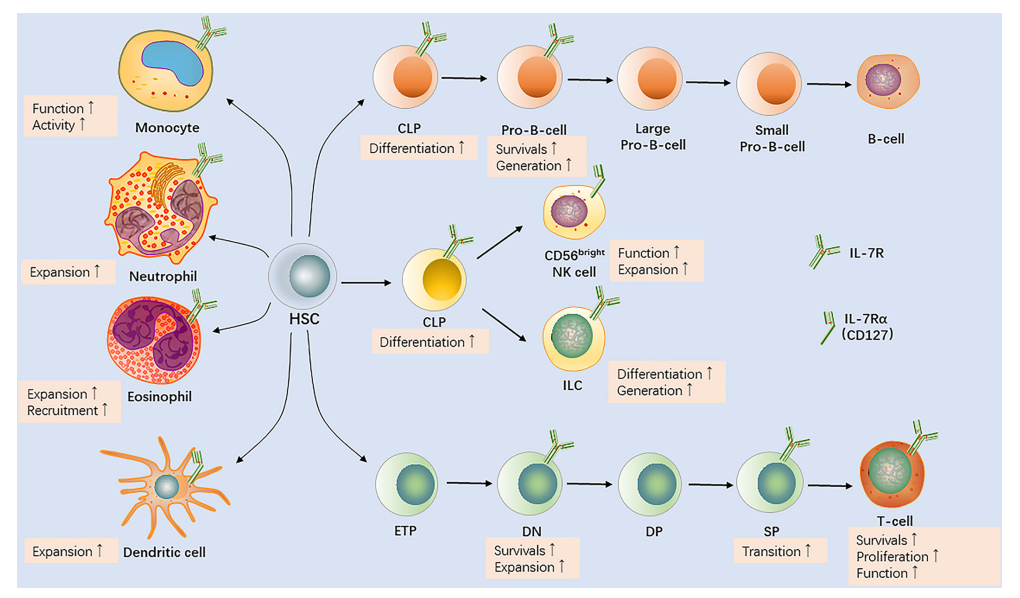

FIGURE 2 | IL-7R expression by immune cells and the effects of interleukin-7 (IL-7) on the development of T cells, B cells, natural killer (NK) cells, innate lymphoid cells (ILCS), monocytes/macrophages, dendritic cells, neutrophils, and eosinophils. HSC, hematopoietic stem cell; CLP, common lymphoid progenitor; ETP, early Tcell lineage progenitor; DN, double-negative; DP, double-positive; SP, single-positive.

development of murine $\mathrm{T}$ cells, demonstrated by the paucity of lymphocytes present in IL-7- and IL-7R-deficient mice and following IL-7 or IL-7R neutralization in vivo. In severe combined immunodeficiency (SCID) resulting from mutations in JAK3, T cells were obviously decreased. JAK3 is indispensable for gamma(c)-dependent signaling because it encodes a Janus family tyrosine kinase that couples gamma(c), indicating that defects in IL-7Ralpha signaling caused $\mathrm{T}^{-} \mathrm{B}^{+} \mathrm{NK}^{+}$SCID (10).

The biological effects of IL-7 on T-cell lymphopoiesis vary for different lineages during the stages of differentiation. Recent studies have shown that the number of early thymic progenitors (ETPs) in mice with impaired IL-7 signaling was significantly decreased, while the number of ETPs in mice with overexpression of IL-7 was greatly increased (11). The findings indicate that IL-7 can promote the development of ETPs. In addition, IL-7 was indispensable during the $\gamma \delta$ TCR (T-cell receptor) rearrangement because $\gamma \delta \mathrm{T}$ cells were completely absent from IL-7 mice. However, when the effect of IL-7 is limited, other elements may compensate. For instance, thymic stromal lymphopoietin (TSLP) also signals through the IL-7R subunit, which can substitute for IL-7 in thymopoiesis to stimulate the proliferation of $\mathrm{CD}_{4}^{+}$single-positive thymocytes and peripheral $\mathrm{T}$ cells, although this is a suboptimal choice. Beyond playing a critical role in the $\mathrm{T}$ lineage progenitor stage of 
thymopoiesis, IL-7 is also crucial for developing double-negative (DN) thymocytes. IL-7 is an efficient growth factor for DN thymocytes and may serve as an amplification step during thymopoiesis. In early thymocytes, IL-7R signals function nonredundantly by promoting proliferation and survival of CD $44^{+} 25^{+} \mathrm{DN}$ thymocytes (so-called DN2 cells) $(12,13)$. Work by Munitic et al. showed that beyond the DN stage, the forced expression of IL-7R $\alpha$ could lead to a diminished size of the DN pool. The researchers suggested that this may occur due to the consumption of IL-7, which then contributed to a reduced supply of IL-7 available for DN thymocytes (14). In contrast to the rigorous requirements for IL-7 signaling in double-negative stage 2 (DN2) thymocytes, IL-7 signaling is commonly extinguished by the immature single positive (ISP) stage of thymocyte development. Notably, work by Yu et al. demonstrated that IL-7R signals act as inhibitors of TCF-1, LEF-1, and RORgammaT, all of which are essential for the transition of DP to SP in the thymus (15). Regulation of IL-7R is also significant during the double-positive stage of development because IL-7R is indispensable for transforming signaled double-positive thymocytes into functionally mature $\mathrm{CD}^{+} \mathrm{T}$ cells (16).

Evidence suggests that IL-7 is an essential requirement for normal thymopoiesis. This raised the possibility that diminished IL-7 production could result in thymic involution and that IL-7 treatment may promote thymopoiesis in lymphopenic individuals. Many researchers have pursued this appealing hypothesis. Although IL-7 therapy in aged mice could not reverse their thymic involution, some reports showed that IL-7 therapy can gradually accelerate recovery of thymic function (17). The multiple functions of IL-7 in T-cell lymphopoiesis have encouraged researchers to apply IL-7 as a therapy for recovering T-cell numbers (18-21). In addition to the application of IL-7 alone, combining IL-7 with other molecules holds potential and has attracted interest. Mamoru et al. demonstrated that when IL7 was induced in the presence of IL-12, the diversity of intratumoral CD8+ T cells increased, and IL-12 function was augmented to promote clonality (22). Similarly, immunocomplexes of IL-7 and $\alpha \mathrm{IL}-7$ mAb M25 (IL-7/M25) were described as super-agonists, remarkably augmenting the size of the T-cell pool. Moreover, the immunocomplex effectively shifted the $\mathrm{CD}^{+}{ }^{+} \mathrm{CD}^{+} \mathrm{T}$ cell ratio in favor of $\mathrm{CD} 8^{+} \mathrm{T}$ cells (23). These studies demonstrate that applying IL-7 to clinical therapeutics effectively boosts $\mathrm{T}$-cell function and restores $\mathrm{T}$ cell numbers to re-establish immune competence (24).

\section{IL-7/IL-7R and T-Cell Survival}

Without external disturbance, the T-cell homeostasis in the peripheral lymphoid compartment is rigorously regulated through turnover, survival, and death. By itself, tonic TCR signaling is not sufficient to keep T cells alive. IL-7 promotes T-cell survival by upregulating the expression level of the Bcl-2 family of molecules, especially $\mathrm{Mcl}-1$ and $\mathrm{Bcl}-2$, which can extensively inhibit the mitochondrial apoptotic pathway. Acting as a critical anti-apoptotic factor, Mcl-1 plays an important role in the survival of single-positive thymocytes, DN thymocytes, naïve T cells, and activated T cells. Moreover,
Mcl-1 functions together with Bcl-xL to promote double-positive thymocyte survival (25). However, some reports challenged the conclusion that IL-7 regulates the expression of two antiapoptotic factors in peripheral $\mathrm{T}$ cells because experiments with CD127 conditional deficient mice revealed no distinct effect on the level of Mcl-1 and Bcl-2 expression compared with normal mice for 3 days, indicating that IL-7 signaling was not required to regulate these molecules $(26,27)$. However, a major limitation is that the half-life of both anti-apoptotic factors could be longer than $72 \mathrm{~h}$.

In addition to dependence on a dynamic balance of proapoptotic and anti-apoptotic signals, it should be emphasized that the capacity of IL-7 to maintain steady metabolismespecially glucose metabolism-is also critical for T-cell survival (28). Previous reports have validated that IL-7 promotes glucose metabolism in vitro to prevent T-cell atrophy (29). Once stimulated by growth factors, T cells increase their rate of glucose uptake and glycolysis. This function is mediated via a signaling mechanism in which STAT5 transcriptional activity promotes Akt activation to regulate glucose uptake and glucose transporter 1 (Glut1) trafficking, essential for IL-7 to prevent $\mathrm{T}$-cell death and maintain homeostasis (30). T cells generally shrink and undergo atrophy when they were transferred into IL-7-deficient hosts (29). Although inhibition of CD127 expression on normal mature T cells did not cause evident changes in total Glut1 levels and glucose uptake, it reduced the rate of glycolysis and induced cell atrophy (26). Taken together, findings demonstrate that IL-7R signaling is essential for promoting $\mathrm{T}$-cell survival through regulating glycolysis. More recently, scientists tried to apply IL-7 to CAR$\mathrm{T}$ cells given the great success chimeric antigen receptor (CAR)engineered T cells showed in cancer treatment. Surprisingly, they found that expression of IL-7 and CCL19 significantly improved $\mathrm{T}$-cell infiltration and survival of CAR-T cells in mouse tumors, enhancing the anti-tumor activity against solid tumors (31).

\section{IL-7/IL-7R AND B CELLS}

\section{IL-7/IL-7R and B-Cell Lymphopoiesis}

Hematopoietic stem cells (HSCs) naturally differentiate into B cells. During the process, cells gradually demonstrate B-cell traits but inhibit the traits of other lineages. IL-7 exerts important functions in mouse B cell development, exemplified by the fact that mice with IL-7 deficiency lack both pre-B cells and mature B cells $(13,32)$. An experiment with IL-7 $\mathrm{R}^{-}$mice detected reduced expression levels of Pax5 in BM cells. Pax5 acted as an essential transcription factor in early B lineage cells (33). More importantly, common lymphoid progenitors (CLPs) lose the ability to differentiate into $\mathrm{B} 220^{+} \mathrm{CD} 19^{+} \mathrm{B}$ lineage cells in the absence of IL-7 (34).

CLPs developed in an IL-7-deficient context possess normal T/NK (natural killer) differentiation potential. However, their B differentiation potential is severely impaired. In limiting dilution assays, CLPs cultured in conditions favorable for B lymphopoiesis generated B lineage cells more than CLPs 
isolated from IL-7 ${ }^{-}$mice cultured in the same conditions. In contrast, enforced expression of EBF (a type of B lineage transcription factor) into CLPs from $\mathrm{IL}^{-} 7^{-}$mice made it possible to restore their capacity to differentiate into B lineage cells (35). Notably, IL-7R signaling has been demonstrated to lead to the expression of EBF by activation of STAT5, a major signaling molecule downstream of the IL-7R signaling pathway. Therefore, IL-7 receptor signaling acts as an important component in forming the transcription factor network during B lymphopoiesis via upregulating EBF, allowing stage transition from the pre-pro-B to further maturational stages (36).

IL-7 is essential for murine B-cell development. However, unlike in mice, the development of human B cells appears to proceed typically in the absence of IL-7. A gene mutation located at the human $\gamma_{c}$ locus may lead to a disease called X-linked severe combined immunodeficiency (X-SCID), characterized by a deficiency of $\mathrm{T}$ and $\mathrm{NK}$ cells in the presence of normal quantities of B cells (10). Indeed, IL-7 reacts with B-cell precursors to show higher survival and proliferation ability by mediating STAT5 (37). Although neonatal cord blood can produce B-cell progenitor cells in the absence of IL-7, IL-7 greatly increases the production of $\mathrm{B}$ cells in co-cultures containing human BM stroma and either adult BM HSCs or cord blood (38). Experiments also revealed the crucial effect of IL-7 on peripheral B-cell numbers. For example, a transient decrease of peripheral B cell numbers could be observed after IL7 therapy, normalizing several weeks after the initiation of treatment. This further suggested that B-cell lymphopoiesis may be affected by the IL-7 levels of peripheral blood (39). The selective cytokine culture experiments conducted by Bruno et al. confirmed that the production of human B-line cells outside the fetal stage depends on the signal mediated by IL-7R $\alpha$, which could be provided by IL-7 or TSLP. The effectiveness of IL-7 on B lymphopoiesis in vivo was demonstrated by the decrease in human B cell progenitor cells after treatment with IL-7 neutralizing antibody in xenografts (40). In addition, the high expression level of IL-7 was reported to be responsible for the increased proportion of immature transitional $\mathrm{B}$ cells in patients infected with HIV-1 $(39,41,42)$.

More recently, experiments by $\mathrm{Yu}$ et al. found that a PLC $\gamma 1 /$ PLC $\gamma 2$ double deficiency in mice resulted in the developmental arrest of early B cells and rendered B-cell progenitors irresponsive to IL-7. Inhibition of mammalian target of rapamycin (mTOR) activation induced by PLC $\gamma /$ PKC impaired IL-7-mediated B-cell development. Briefly, IL-7 receptors regulated early $\mathrm{B}$ lymphopoiesis by activating the mTOR via PLC $\gamma / D A G / P K C$ signaling (43). Despite its positive effect on Bcell production, IL-7 has been demonstrated to be an unfavorable prognostic factor affecting clinical outcomes in both mice and humans. For example, compared with healthy individuals, patients with Hodgkin's lymphoma display higher serum levels of IL-7, and IL-7 mRNA-specific signals are detectable in tumor tissues (44). Lymphomas are also frequently observed in IL-7 transgenic mice (45). The role of IL-7 in the pathogenesis of types of lymphoma and leukemia is documented in several studies $(46,47)$.

\section{IL-7/IL-7R and B-Cell Survival}

IL-7 promotes B-cell survival by modulating pro-apoptotic production (such as Bax, Bad, and Bim) and anti-apoptotic factors (such as Bcl-2, Bcl-xL, and Mcl-1). Studies have shown that different regions of the IL-7 receptors initiated the signal transduction pathways that regulate the Bcl-2 family, including the synthesis of $\mathrm{Bcl}-2$, phosphorylation of $\mathrm{Bad}$, and cytosolic retention of $\operatorname{Bax}(48)$. Short-term culture of immature thymocytes with IL-7 causes an increase in Bcl-2 expression and cell survival (49). Mcl-1 is another critical factor associated with the survival of B cells, and STAT5 regulates its expression directly (50). Defects in Mcl-1 expression increase apoptosis of B cells and arrest the development at the pro-B-cell stage. In thymocytes deficient in recombination activating gene 2, exposure to IL-7 stimulation leads to a significant increase in Mcl-1mRNA levels within $30 \mathrm{~min}$ (51). PI3K/Akt and JAK/ STAT pathways also play an important role in mediating the survival responses of IL-7. PI3-K initiates Akt-dependent phosphorylation of $\mathrm{Bad}$, which is conducive to maintaining $\mathrm{Bad}$ in the cytosol. To prevent apoptosis, this procedure requires the activation by $\mathrm{IL}-7 \mathrm{R}$ signaling (52). Bax is a significant pro-apoptotic factor in B-cell development, and mice lacking the signaling component JAK3 or IL-7R display greatly increased Bax levels $(53,54)$. More interestingly, although $B$ cells are insensitive to IL-7 (due to the lack of expression of IL$7 \mathrm{R}$ on mature $\mathrm{B}$ cells), high concentrations of IL-7 promote Bcell survival and increase antibody production in the presence of $\mathrm{T}$ cells without using any other B-cell stimulatory signal. The mechanism is that IL-7 promotes B cell activation through stimulating expression of CD70 on $\mathrm{CD}^{+}$memory cells. IL-7 treatment also triggers resting peripheral $\mathrm{T}$ cells to secrete BAFF, thus promoting the survival of B cells (55).

\section{IL-7/IL-7R AND NK CELLS}

Human NK cells comprise approximately $15 \%$ of all circulating lymphocytes. In humans, NK cells can be divided into two subsets: CD56 ${ }^{\text {bright }}$ and CD56 ${ }^{\text {dim }}$ subsets, based on their localization and the cell-surface density of CD56 (56). The two subsets have distinct functional properties. The CD56 ${ }^{\text {bright }} \mathrm{NK}$ population produces large amounts of diverse cytokines. In contrast, CD56 ${ }^{\mathrm{dim}} \mathrm{NK}$ population possesses high cytotoxic activity. We already know that CD127 is expressed predominantly on CD56 ${ }^{\text {bright }} \mathrm{NK}$ cells (57). More importantly, CD127 acts as a molecular marker in the development of mouse NK cells derived from the thymus. CD127 NK cells originating from the thymus repopulate in peripheral lymphoid organs, where IL-7 strictly regulates their homeostasis (58). Studies report that IL-7 has redundant functions for generating NK cell precursors and immature NK cells. It also plays a critical role in the normal homeostasis of mature NK cells in the spleen (59-61).

Vosshenrich et al. compared the generation of thymic NK cells in Rag2 IL7 ${ }^{+}$and Rag2 IL7 ${ }^{-}$mice. The phenotype and absolute number in the spleen and BM were not significantly different. However, mice lacking in IL-7 had rare thymic 
$\mathrm{CD} 127^{+} \mathrm{NK}$ cells, indicating that IL-7 is critical for the homeostasis (58). The authors assessed the NK cell number that the thymus contributed to the peripheral NK cell pool and found that considerable $\mathrm{CD} 127^{+} \mathrm{NK}$ cells were exported to peripheral organs (58). However, in contrast to observations in mice, Michaud et al. assessed the IL-7R $\alpha$ expression levels in mature NK cells isolated from human peripheral blood, and found that IL-7R $\alpha^{+} \mathrm{CD} 56$ bright $\mathrm{NK}$ cells were independent of thymic maturation because the NK cells extracted from athymic patients expressed IL-7R $\alpha$. Moreover, the team confirmed that IL-7 enhanced the survival of CD56 ${ }^{\text {bright }} \mathrm{NK}$ cells by increasing the expression of Bcl-2 (57).

Several lines of evidence confirm that IL-7 is extremely important in disease control through regulating the biological functions and homeostasis of NK cells. For example, patients with multiple sclerosis (MS) have decreased NK cell numbers and impairment of NK cell functions. The levels of IL-7 and IL$7 \mathrm{R} \alpha$ in $\mathrm{MS}$ patients affect the functional responsiveness of NK cells. IL-7 induces an increase of IFN- $\gamma$ production in CD56 $6^{\text {bright }}$ NK cells and a pronounced enhancement of cytotoxicity in NK cells from patients with MS (62). In hepatitis C virus (HCV) mono-infection and HIV-HCV co-infection, IL-7 enhances NKcell degranulation and promotes NK-cell cytolysis of target cells (63). Correspondingly, by using $\mathrm{CD}^{-} \mathrm{CD} 16^{+} \mathrm{CD} 56^{+}$cells from HIV-positive and -negative donors, Lum et al. showed that IL-7 could augment NK function by upregulating Fas ligand (64).

\section{IL-7/IL-7R AND ILCS}

Innate lymphoid cells (ILCs) are a recently discovered family of lymphoid cells important for eliminating external pathogens, tissue development and remodeling, and immune defense at multiple mucosal sites (65). ILCs are categorized into three broad classes: ILC1s, ILC2s, and ILC3s. A further subset of ILCs is LTi, namely, lymphoid tissue inducer cells. NK cells are similar to ILC1s but are not considered part of the ILC subset. IL-7 is involved in the development of all ILC subsets, as demonstrated by animal experiments. For instance, compared with wild-type (WT) mice, only a marginal reduction of ILC1s was observed in IL-7R ${ }^{-}$mice or IL-15 ${ }^{-}$mice. In contrast, ILC1s in IL-7R ${ }^{-}$IL-15R mice were significantly reduced, indicating a synergistic effect from IL-7 in maintaining ILC1s (66).

One study suggested that IL-7 is critical for the survival and maintenance of ILC2s in the tissue (67). The dependency of transcription factors may shed light on the mechanism of IL-7's mediation in developing ILCs. Id $2^{+}$CHILPs (common helper innate lymphoid precursor cells) can generate ILC subsets (ILC1s, ILC2s, ILC3s, and LTi), and a transcription factor called NF1IL3 has been confirmed as indispensable for the generation of CHILPs and expression of Id2 (68). IL-7 promotes the expression of NFIL3 (68), and therefore, a deficiency in IL-7 impairs the development of all ILC subsets. In addition, IL-7 and its receptor drive the differentiation and generation of ILCs by initiating the expression of transcription factor Sall3 in CHILPs (69). Recent work by Yang et al. emphasized the importance of IL-7 for the development of ILC3s, and found that IL-7-dependent maintenance of ILC3s resulted in the normal entry of lymphocytes into lymph nodes (70).

\section{IL-7/IL-7R AND MONOCYTES/ MACROPHAGES}

Information about the effects of IL-7 on monocytes is sparse and the role of IL-7 in the development of $\mathrm{CD}_{14}{ }^{+}$monocytes is not yet clarified. Studies from the last century described the destruction of monocyte-derived macrophages (MDMs) infected with Mycobacterium avium mediated by IL-7 (71). The anti-tumor cytotoxic and antimicrobial effects of monocytes/macrophages treated with IL-7 have also been described $(71,72)$. In patients with autoimmune disorders, IL7 combined with blood monocytes to maintain human $\mathrm{CD} 4^{+}$ memory cells with mixed regulatory/helper functions (73). Recently, scientists have reported studies on the in vitro effects of IL-7. An increased HLA-DR expression of monocytes in the presence of IL-7 has been reported. Thus, increased antigen presentation may improve the monocyte effect mechanism in vitro (74). Li et al. demonstrated that administration of IL-7 in vivo significantly augmented the activity of lung-resident purified monocytes. Treatment with IL-7 resulted in elevated STAT5 phosphorylation, increased pro-inflammatory cytokine secretion, and promotion of cellular proliferation. Activation of $\mathrm{CD} 4^{+} \mathrm{T}$ cells was induced by monocytes and further enhanced after treatment with IL-7 (75). IL-7 also induced the recruitment of monocytes to the endothelium and promoted the cytokine secretion of $\mathrm{CD}_{14}{ }^{+}$monocytes $(9,72,76)$. However, the biological relevance of these findings remains elusive because of the relatively low IL-7R expression in monocytes and the indirect effects of other cells and cytokines.

\section{IL-7/IL-7R AND DENDRITIC CELLS}

Dendritic cells (DCs) have long been recognized as important components of immune cells. To date, there is no unified view on the role of IL-7 in DCs. Katz and Takeuchi found that DCs were independent of IL-7, and IL-7R was not required to develop DCs (77). In their experiments, IL-7 $\mathrm{R}^{-} \mathrm{BM}$ cells were transferred into sub-lethally irradiated WT mice. They found that IL-7R $\alpha$ knockout (KO) cells reconstituted various DC subsets, and thymic, splenic, peripheral lymph nodes ( $\mathrm{pLN}$ ) and thymic-plasmacytoid DCs were reconstituted by IL-7R $\alpha \mathrm{KO}$ and WT donor cells. However, their study was limited by the single experiment design and difficulties in determining the proportion of DCs from donors. In contrast to Katz and Takeuchi's work, Vogt et al. used multiple in vivo models. Each model lacking in IL-7 demonstrated reduced DC numbers, strongly suggesting that precursors of both conventional DCs and plasmacytoid DCs depended on IL-7 (78). The addition of IL-7 to fetal thymus organ cultures (FTOC) led to the continuous generation of large numbers of functional DCs. Nevertheless, 
endogenous deficiency of IL-7 reduced DC numbers drastically (79). Saunders et al. noted that after a 4-day culture period with a mixture of several cytokines, including IL-7, the mice thymic precursors proliferated and differentiated to DCs instead of Tlineage cells (80). Marquez et al. considered that human intrathymic precursors can differentiate to T-lineage cells if cultured in the presence of IL-7, and can then simultaneously develop into both monocytes and DCs (81). To date, there is limited research on the precise mechanism of IL-7 in DC development. However, granulocyte-macrophage colony-stimulating factor (GM-CSF) was confirmed to regulate the development of cDCs (conventional dendritic cells) and pDCs (plasmacytoid dendritic cells) by employing STAT5 to inhibit the IRF8 and the transcriptional network in $\operatorname{lin}^{-} \mathrm{Flt}^{+}{ }^{+}$progenitors (82). IL-7 is known to trigger the phosphorylation of STAT5 $(83,84)$, and thus, it seems likely that IL-7R could be an important signal upstream of STAT5 in DC precursors.

Moore et al. (85) set out to elucidate the mechanism of IL-7's influence on DC biology. They examined the corticomedullary structure and DC populations in IL-7R thymus, showing that a loss of IL-7R $\mathrm{R}^{-}$dependent cells led to an inverted ratio of medullary thymic epithelial cells (mTECs) to cortical thymic epithelial cells (cTECs). An impact on the accumulation of three thymic DC subsets was also noted. Their BM chimera experiments revealed that the deficiency in the DC compartment from IL-7R ${ }^{-}$thymus is cell-extrinsic. Therefore, although there is no intrinsic need for IL-7 during the development of DCs derived from thymic tissue, IL-7 is extremely important for establishing microenvironments that allow the accumulation of thymic DCs.

\section{IL-7/IL-7R AND NEUTROPHILS}

IL-7 receptors are also expressed in neutrophils, but their role in neutrophil biology has attracted less attention from scientists compared with other immune cells. In the last century, researchers found that intravenous injection of IL-7 into mice increased neutrophils $(86,87)$. Jiang et al. introduced the IL-7R gene into IL-7 $\mathrm{R}^{-} \mathrm{BM}$ progenitors to test the feasibility of IL-7R transgenic therapy. An unanticipated result was the almost logarithmic increase in neutrophils (88). In addition to affecting the number of neutrophils, IL-7 treatment has been reported to accelerate the recruitment of neutrophils by promoting T-cell IL-17 secretion (8). This is because IL-17 acts on mesothelial cells to trigger the secretion of CXCL1/KC and CXCL2/MIP-2 (89), which have been demonstrated as essential for the promotion of neutrophil recruitment and granulopoiesis $(90,91)$. However, IL-7 only accelerated neutrophil recruitment, and the acceleration of its activation or functionality was not observed in the study (8).

\section{IL-7/IL-7R AND EOSINOPHILS}

There are few reports of responsiveness to IL-7 by eosinophils. Vellenga et al. reported CD127 expression on eosinophil progenitors in BM and showed that IL-7 promoted eosinophil colony formation from human BM cells (92). In addition, mRNA for CD127 and CD132 were found to be expressed in human blood eosinophils (93). Some primary studies have indirectly confirmed that IL-7 can increase the production of eosinophils. For example, eosinophil infiltration has been observed in mice colonic mucosa after being treated with overproduction of IL-7 in the colon (94). Similar results have been reported in murine tumors engineered to overexpress IL-7 $(95,96)$. Conversely, a lack of eosinophils was observed in mice treated with targeted IL7 deletion (97). Western blotting analysis by Kelly et al. confirmed the existence of IL-7R $\alpha$ in highly purified human blood eosinophils and revealed its novel property of upregulating the activation marker CD69. More importantly, it demonstrated that IL-7 promotes the survival of human eosinophils (98).

\section{Clinical Studies on IL-7 Therapy}

Clinical studies with IL-7 consistently demonstrates effective results, especially for acute and chronic infectious diseases. For example, a case report of a patient with progressive multifocal leukoencephalopathy (PML) showed that IL-7 decreased circulating John Cunningham (JC) virus, rapidly increased lymphocytes, and contributed to disease resolution (99). Sepsis is a perennial problem, but many high-profile and cutting-edge therapies are ineffective for sepsis management. The first trial of immunoadjuvant therapy targeting defects in adaptive immunity in septic patients demonstrated that IL-7 restored lymphocytes in septic shock (100). Encouragingly, IL-7 therapy also proved effective for novel coronavirus disease (COVID-19), which represents the greatest medical challenge in decades. In a recent case series, 12 critically ill patients with COVID-19 and severe lymphopenia were treated with IL-7 therapy. The lymphocyte count of the IL-7 group was more than double that of the control group (101).

Highly active antiretroviral therapy (HAART) has been recognized as effective in the treatment of HIV infection. However, while HAART almost completely inhibits viral replication, it fails to restore immune function. Preliminary clinical trial results demonstrated that IL-7 therapy improved proliferation and survival of $\mathrm{T}$ cells in HAART-treated $\mathrm{HIV}^{+}$ individuals (102). This suggests that HAART may translate into more favorable clinical outcomes with the use of IL-7. Similarly, Sereti et al. confirmed that IL-7 administration drove T-cell cycle entry and expansion in HIV-1 infection (103). Moreover, administration of recombinant human interleukin-7 (rhIL-7) improved the gut mucosal abnormalities of chronic HIV infection and attenuated the systemic inflammatory and coagulation abnormalities linked to it (104).

In addition to IL-7's application in infectious diseases, current understanding of cancer immunotherapy suggests that IL-7 therapy has great potential for cancer treatment. In the first clinical trial with humans, 16 patients with refractory cancer were treated with rhIL-7 every other day for a total of 14 days. Substantial dose-dependent increases in the numbers of circulating $\mathrm{CD}^{+}$and $\mathrm{CD} 8^{+} \mathrm{T}$ cells were observed in the trial, with increases peaking at 3 weeks after the IL-7 therapy and being sustained for at least 2 months (105). In lymphopenic 
metastatic breast cancers, rhIL-7 administration before chemotherapy significantly increased $\mathrm{CD}^{+}$and $\mathrm{CD}^{+}{ }^{+}$T-cell counts, but there was no obvious increase in the expression level of inflammatory cytokine (20). Preclinical studies have validated the anti-tumor potency of IL-7 therapy. Intra-tumoral delivery of IL-7-transduced DCs resulted in increased production of interferon (IFN) and GM-CSF, thereby inducing superior antitumor responses (106). In addition to using IL-7 alone, efforts to combine IL-7 with other molecules have also occurred. A group of researchers demonstrated that therapy using an IL-7 complex, formed with an IL-7R-Fc, induced anti-tumor responses by increasing tumor infiltration of $\mathrm{T}$ cells through CXCR3 chemokine signaling (107).

\section{CONCLUSION AND UNANSWERED QUESTIONS}

The subject of IL-7 function and regulation is challenging and highlights the complexity of this cytokine. Several general conclusions can be drawn from the review. First, most types of immune cells are rigorously regulated by IL-7 throughout their lifespan. Second, although common effects exist, the ultimate influence of IL-7 regulation differs according to the cell type. Finally, the expression of IL-7 positively regulates the expression of pro-inflammatory cells and cytokines, indicating that the application of IL-7 is a promising therapeutic strategy for many diseases.

\section{REFERENCES}

1. Namen AE, Lupton S, Hjerrild K, Wignall J, Mochizuki DY, Schmierer A, et al. Stimulation of B-Cell Progenitors by Cloned Murine Interleukin-7. Nature (1988) 333(6173):571-3. doi: 10.1038/333571a0

2. Alpdogan O, van den Brink MR. IL-7 and IL-15: Therapeutic Cytokines for Immunodeficiency. Trends Immunol (2005) 26(1):56-64. doi: 10.1016/ j.it.2004.11.002

3. Barata JT, Durum SK, Seddon B. Flip the Coin: IL-7 and IL-7R in Health and Disease. Nat Immunol (2019) 20(12):1584-93. doi: 10.1038/s41590-0190479-x

4. Ingley E, Klinken SP. Cross-Regulation of JAK and Src Kinases. Growth Factors (2006) 24(1):89-95. doi: 10.1080/08977190500368031

5. Baracho GV, Miletic AV, Omori SA, Cato MH, Rickert RC. Emergence of the PI3-Kinase Pathway as a Central Modulator of Normal and Aberrant B Cell Differentiation. Curr Opin Immunol (2011) 23(2):178-83. doi: 10.1016/ j.coi.2011.01.001

6. Bradley LM, Haynes L, Swain SL. IL-7: Maintaining T-Cell Memory and Achieving Homeostasis. Trends Immunol (2005) 26(3):172-6. doi: 10.1016/ j.it.2005.01.004

7. Corfe SA, Paige CJ. The Many Roles of IL-7 in B Cell Development; Mediator of Survival, Proliferation and Differentiation. Semin Immunol (2012) 24(3):198-208. doi: 10.1016/j.smim.2012.02.001

8. Kasten KR, Prakash PS, Unsinger J, Goetzman HS, England LG, Cave CM, et al. Interleukin-7 (IL-7) Treatment Accelerates Neutrophil Recruitment Through Gamma Delta T-Cell IL-17 Production in a Murine Model of Sepsis. Infect Immun (2010) 78(11):4714-22. doi: 10.1128/IAI.00456-10

9. Li R, Paul A, Ko KW, Sheldon M, Rich BE, Terashima T, et al. Interleukin-7 Induces Recruitment of Monocytes/Macrophages to Endothelium. Eur Heart J (2012) 33(24):3114-23. doi: 10.1093/eurheartj/ehr245
Several unanswered questions and challenges remain to be solved. For instance, the cells induced to secrete IL-7 during immune responses to specific diseases are not known, and we do not yet know the appropriate amount of IL-7 for different stages of diseases. When is the most suitable time to apply IL-7 to enhance immune reconstitution after infection with a specific pathogen? What is the hierarchy of transcription factor binding to IL-7 regulatory elements in different types of cells? However, many of these questions may be solved by further animal experiments and clinical trials, and combining traditional biochemical methods and high-throughput approaches to clarify molecular signal transduction pathways.

\section{AUTHOR CONTRIBUTIONS}

DC and Z-HT participated in the design and drafted the manuscript. T-XT, HD, and X-PY participated in critical discussions and revised the manuscript. Z-HT supervised the project. All authors contributed to the article and approved the submitted version.

\section{FUNDING}

This work was supported in part by the National Natural Science Foundation of China 81873870 (Z-HT).

10. Puel A, Ziegler SF, Buckley RH, Leonard WJ. Defective IL7R Expression in T $(-) \mathrm{B}(+) \mathrm{NK}(+)$ Severe Combined Immunodeficiency. Nat Genet (1998) 20 (4):394-7. doi: 10.1038/3877

11. Plumb AW, Sheikh A, Carlow DA, Patton DT, Ziltener HJ, Abraham N Interleukin-7 in the Transition of Bone Marrow Progenitors to the Thymus. Immunol Cell Biol (2017) 95(10):916-24. doi: 10.1038/icb.2017.68

12. Akashi K, Kondo M, von Freeden-Jeffry U, Murray R, Weissman IL. Bcl-2 Rescues T Lymphopoiesis in Interleukin-7 Receptor-Deficient Mice. Cell (1997) 89(7):1033-41. doi: 10.1016/s0092-8674(00)80291-3

13. Peschon JJ, Morrissey PJ, Grabstein KH, Ramsdell FJ, Maraskovsky E, Gliniak BC, et al. Early Lymphocyte Expansion Is Severely Impaired in Interleukin 7 Receptor-Deficient Mice. J Exp Med (1994) 180(5):1955-60. doi: 10.1084/jem.180.5.1955

14. Munitic I, Williams JA, Yang Y, Dong B, Lucas PJ, El Kassar N, et al. Dynamic Regulation of IL-7 Receptor Expression is Required for Normal Thymopoiesis. Blood (2004) 104(13):4165-72. doi: 10.1182/blood-2004-06-2484

15. Yu Q, Erman B, Park JH, Feigenbaum L, Singer A. IL-7 Receptor Signals Inhibit Expression of Transcription Factors TCF-1, LEF-1, and RORgammat: Impact on Thymocyte Development. J Exp Med (2004) 200 (6):797-803. doi: 10.1084/jem.20032183

16. Yu Q, Erman B, Bhandoola A, Sharrow SO, Singer A. In Vitro Evidence That Cytokine Receptor Signals are Required for Differentiation of Double Positive Thymocytes Into Functionally Mature CD8+ T Cells. J Exp Med (2003) 197(4):475-87. doi: 10.1084/jem.20021765

17. Mackall CL, Gress RE. Thymic Aging and T-Cell Regeneration. Immunol Rev (1997) 160:91-102. doi: 10.1111/j.1600-065x.1997.tb01030.x

18. Perales MA, Goldberg JD, Yuan J, Koehne G, Lechner L, Papadopoulos EB, et al. Recombinant Human Interleukin-7 (CYT107) Promotes T-Cell Recovery After Allogeneic Stem Cell Transplantation. Blood (2012) 120 (24):4882-91. doi: 10.1182/blood-2012-06-437236 
19. Sheikh V, Porter BO, DerSimonian R, Kovacs SB, Thompson WL, PerezDiez A, et al. Administration of Interleukin-7 Increases CD4 T Cells in Idiopathic CD4 Lymphocytopenia. Blood (2016) 127(8):977-88. doi: 10.1182/blood-2015-05-645077

20. Tredan O, Menetrier-Caux C, Ray-Coquard I, Garin G, Cropet C, Verronese E, et al. ELYPSE-7: A Randomized Placebo-Controlled Phase IIa Trial With CYT107 Exploring the Restoration of CD4+ Lymphocyte Count in Lymphopenic Metastatic Breast Cancer Patients. Ann Oncol (2015) 26 (7):1353-62. doi: 10.1093/annonc/mdv173

21. Bullenkamp J, Mengoni V, Kaur S, Chhetri I, Dimou P, Astroulakis ZMJ, et al. Interleukin-7 and Interleukin-15 Drive CD4+CD28null T Lymphocyte Expansion and Function in Patients With Acute Coronary Syndrome. Cardiovasc Res (2021) 117(8):1935-48. doi: 10.1093/cvr/cvaa202

22. Tasaki M, Yamashita M, Arai Y, Nakamura T, Nakao S. IL-7 Coupled With IL-12 Increases Intratumoral T Cell Clonality, Leading to Complete Regression of Non-Immunogenic Tumors. Cancer Immunol Immunother (2021) 70(12):3557-71. doi: 10.1007/s00262-021-02947-y

23. Hrabos D, Hnizdilova T, Tomala J, Uhlik J, Kovar M. IL-7/alphaIL-7 mAb M25 Immunocomplexes Expand CD8(+) T Cells But Paradoxically Abrogate the Antitumor Activity of CTLA-4 and PD-1 Blockage. Cytokine (2020) 133:155174. doi: 10.1016/j.cyto.2020.155174

24. Mackall CL, Fry TJ, Gress RE. Harnessing the Biology of IL-7 for Therapeutic Application. Nat Rev Immunol (2011) 11(5):330-42. doi: $10.1038 /$ nri2970

25. Dzhagalov I, Dunkle A, He YW. The Anti-Apoptotic Bcl-2 Family Member Mcl-1 Promotes T Lymphocyte Survival at Multiple Stages. I Immunol (2008) 181(1):521-8. doi: 10.4049/jimmunol.181.1.521

26. Jacobs SR, Michalek RD, Rathmell JC. IL-7 is Essential for Homeostatic Control of T Cell Metabolism In Vivo. J Immunol (2010) 184(7):3461-9. doi: 10.4049/jimmunol.0902593

27. Pearson C, Silva A, Saini M, Seddon B. IL-7 Determines the Homeostatic Fitness of T Cells by Distinct Mechanisms at Different Signalling Thresholds In Vivo. Eur J Immunol (2011) 41(12):3656-66. doi: 10.1002/eji.201141514

28. Michalek RD, Rathmell JC. The Metabolic Life and Times of a T-Cell. Immunol Rev (2010) 236:190-202. doi: 10.1111/j.1600-065X.2010.00911.x

29. Rathmell JC, Farkash EA, Gao W, Thompson CB. IL-7 Enhances the Survival and Maintains the Size of Naive T Cells. J Immunol (2001) 167 (12):6869-76. doi: 10.4049/jimmunol.167.12.6869

30. Wofford JA, Wieman HL, Jacobs SR, Zhao Y, Rathmell JC. IL-7 Promotes Glut1 Trafficking and Glucose Uptake via STAT5-Mediated Activation of Akt to Support T-Cell Survival. Blood (2008) 111(4):2101-11. doi: 10.1182/ blood-2007-06-096297

31. Pang N, Shi J, Qin L, Chen A, Tang Y, Yang H, et al. IL-7 and CCL19Secreting CAR-T Cell Therapy for Tumors With Positive Glypican-3 or Mesothelin. J Hematol Oncol (2021) 14(1):118. doi: 10.1186/s13045-02101128-9

32. von Freeden-Jeffry U, Vieira P, Lucian LA, McNeil T, Burdach SE, Murray R. Lymphopenia in Interleukin (IL)-7 Gene-Deleted Mice Identifies IL-7 as a Nonredundant Cytokine. J Exp Med (1995) 181(4):1519-26. doi: 10.1084/ jem.181.4.1519

33. Corcoran AE, Riddell A, Krooshoop D, Venkitaraman AR. Impaired Immunoglobulin Gene Rearrangement in Mice Lacking the IL-7 Receptor. Nature (1998) 391(6670):904-7. doi: 10.1038/36122

34. Miller JP, Izon D, DeMuth W, Gerstein R, Bhandoola A, Allman D. The Earliest Step in B Lineage Differentiation From Common Lymphoid Progenitors Is Critically Dependent Upon Interleukin 7. J Exp Med (2002) 196(5):705-11. doi: 10.1084/jem.20020784

35. Dias S, Silva H Jr, Cumano A, Vieira P. Interleukin-7 is Necessary to Maintain the B Cell Potential in Common Lymphoid Progenitors. J Exp Med (2005) 201(6):971-9. doi: 10.1084/jem.20042393

36. Kikuchi K, Lai AY, Hsu CL, Kondo M. IL-7 Receptor Signaling is Necessary for Stage Transition in Adult B Cell Development Through Up-Regulation of EBF. J Exp Med (2005) 201(8):1197-203. doi: 10.1084/jem.20050158

37. Johnson SE, Shah N, Panoskaltsis-Mortari A, LeBien TW. Murine and Human IL-7 Activate STAT5 and Induce Proliferation of Normal Human Pro-B Cells. J Immunol (2005) 175(11):7325-31. doi: 10.4049/jimmunol.175.11.7325

38. Parrish YK, Baez I, Milford TA, Benitez A, Galloway N, Rogerio JW, et al. IL7 Dependence in Human B Lymphopoiesis Increases During Progression of
Ontogeny From Cord Blood to Bone Marrow. J Immunol (2009) 182 (7):4255-66. doi: 10.4049/jimmunol.0800489

39. Sportes C, Babb RR, Krumlauf MC, Hakim FT, Steinberg SM, Chow CK, et al. Phase I Study of Recombinant Human Interleukin-7 Administration in Subjects With Refractory Malignancy. Clin Cancer Res (2010) 16(2):727-35. doi: 10.1158/1078-0432.CCR-09-1303

40. Milford TA, Su RJ, Francis OL, Baez I, Martinez SR, Coats JS, et al. TSLP or IL-7 Provide an IL-7Ralpha Signal That is Critical for Human B Lymphopoiesis. Eur J Immunol (2016) 46(9):2155-61. doi: 10.1002/ eji.201646307

41. Malaspina A, Moir S, Ho J, Wang W, Howell ML, O'Shea MA, et al. Appearance of Immature/Transitional B Cells in HIV-Infected Individuals With Advanced Disease: Correlation With Increased IL-7. Proc Natl Acad Sci USA (2006) 103(7):2262-7. doi: 10.1073/pnas.0511094103

42. Malaspina A, Moir S, Chaitt DG, Rehm CA, Kottilil S, Falloon J, et al. Idiopathic CD4+ T Lymphocytopenia is Associated With Increases in Immature/Transitional B Cells and Serum Levels of IL-7. Blood (2007) 109(5):2086-8. doi: 10.1182/blood-2006-06-031385

43. Yu M, Chen Y, Zeng H, Zheng Y, Fu G, Zhu W, et al. PLCgammaDependent mTOR Signalling Controls IL-7-Mediated Early B Cell Development. Nat Commun (2017) 8(1):1457. doi: 10.1038/s41467-01701388-5

44. Foss HD, Hummel M, Gottstein S, Ziemann K, Falini B, Herbst H, et al. Frequent Expression of IL-7 Gene Transcripts in Tumor Cells of Classical Hodgkin's Disease. Am J Pathol (1995) 146(1):33-9.

45. Rich BE, Campos-Torres J, Tepper RI, Moreadith RW, Leder P. Cutaneous Lymphoproliferation and Lymphomas in Interleukin 7 Transgenic Mice. J Exp Med (1993) 177(2):305-16. doi: 10.1084/jem.177.2.305

46. Brown VI, Hulitt J, Fish J, Sheen C, Bruno M, Xu Q, et al. Thymic StromalDerived Lymphopoietin Induces Proliferation of Pre-B Leukemia and Antagonizes mTOR Inhibitors, Suggesting a Role for Interleukin-7Ralpha Signaling. Cancer Res (2007) 67(20):9963-70. doi: 10.1158/0008-5472.CAN06-4704

47. Yamanaka K, Clark R, Rich B, Dowgiert R, Hirahara K, Hurwitz D, et al. Skin-Derived Interleukin-7 Contributes to the Proliferation of Lymphocytes in Cutaneous T-Cell Lymphoma. Blood (2006) 107(6):2440-5. doi: 10.1182/ blood-2005-03-1139

48. Jiang Q, Li WQ, Hofmeister RR, Young HA, Hodge DR, Keller JR, et al. Distinct Regions of the Interleukin-7 Receptor Regulate Different Bcl2 Family Members. Mol Cell Biol (2004) 24(14):6501-13. doi: 10.1128/ MCB.24.14.6501-6513.2004

49. von Freeden-Jeffry U, Solvason N, Howard M, Murray R. The Earliest T Lineage-Committed Cells Depend on IL-7 for Bcl-2 Expression and Normal Cell Cycle Progression. Immunity (1997) 7(1):147-54. doi: 10.1016/s10747613(00)80517-8

50. Malin S, McManus S, Cobaleda C, Novatchkova M, Delogu A, Bouillet P, et al. Role of STAT5 in Controlling Cell Survival and Immunoglobulin Gene Recombination During Pro-B Cell Development. Nat Immunol (2010) 11 (2):171-9. doi: 10.1038/ni.1827

51. Opferman JT, Letai A, Beard C, Sorcinelli MD, Ong CC, Korsmeyer SJ. Development and Maintenance of $\mathrm{B}$ and $\mathrm{T}$ Lymphocytes Requires Antiapoptotic MCL-1. Nature (2003) 426(6967):671-6. doi: 10.1038/ nature 02067

52. Franke TF, Kaplan DR, Cantley LC. PI3K: Downstream AKTion Blocks Apoptosis. Cell (1997) 88(4):435-7. doi: 10.1016/s0092-8674(00)81883-8

53. Wen R, Wang D, McKay C, Bunting KD, Marine JC, Vanin EF, et al. Jak3 Selectively Regulates Bax and Bcl-2 Expression to Promote T-Cell Development. Mol Cell Biol (2001) 21(2):678-89. doi: 10.1128/MCB.21.2.678-689.2001

54. Lu L, Chaudhury P, Osmond DG. Regulation of Cell Survival During B Lymphopoiesis: Apoptosis and Bcl-2/Bax Content of Precursor B Cells in Bone Marrow of Mice With Altered Expression of IL-7 and RecombinaseActivating Gene-2. J Immunol (1999) 162(4):1931-40.

55. Sammicheli S, Ruffin N, Lantto R, Vivar N, Chiodi F, Rethi B. IL-7 Modulates B Cells Survival and Activation by Inducing BAFF and CD70 Expression in T Cells. J Autoimmun (2012) 38(4):304-14. doi: 10.1016/ j.jaut.2012.01.012

56. Lanier LL, Le AM, Civin CI, Loken MR, Phillips JH. The Relationship of CD16 (Leu-11) and Leu-19 (NKH-1) Antigen Expression on Human 
Peripheral Blood NK Cells and Cytotoxic T Lymphocytes. J Immunol (1986) 136(12):4480-6.

57. Michaud A, Dardari R, Charrier E, Cordeiro P, Herblot S, Duval M. IL-7 Enhances Survival of Human CD56bright NK Cells. J Immunother (2010) 33 (4):382-90. doi: 10.1097/CJI.0b013e3181cd872d

58. Vosshenrich CA, Garcia-Ojeda ME, Samson-Villeger SI, Pasqualetto V, Enault L, Richard-Le Goff O, et al. A Thymic Pathway of Mouse Natural Killer Cell Development Characterized by Expression of GATA-3 and CD127. Nat Immunol (2006) 7(11):1217-24. doi: 10.1038/ni1395

59. Ranson T, Vosshenrich CA, Corcuff E, Richard O, Muller W, Di Santo JP. IL-15 Is an Essential Mediator of Peripheral NK-Cell Homeostasis. Blood (2003) 101(12):4887-93. doi: 10.1182/blood-2002-11-3392

60. He YW, Malek TR. Interleukin-7 Receptor Alpha is Essential for the Development of Gamma Delta + T Cells, But Not Natural Killer Cells. J Exp Med (1996) 184(1):289-93. doi: 10.1084/jem.184.1.289

61. Vosshenrich CA, Ranson T, Samson SI, Corcuff E, Colucci F, Rosmaraki EE, et al. Roles for Common Cytokine Receptor Gamma-Chain-Dependent Cytokines in the Generation, Differentiation, and Maturation of NK Cell Precursors and Peripheral NK Cells In Vivo. J Immunol (2005) 174(3):121321. doi: 10.4049/jimmunol.174.3.1213

62. Su N, Shi SX, Zhu X, Borazanci A, Shi FD, Gan Y. Interleukin-7 Expression and its Effect on Natural Killer Cells in Patients With Multiple Sclerosis. J Neuroimmunol (2014) 276(1-2):180-6. doi: 10.1016/j.jneuroim.2014.08.618

63. Judge CJ, Kostadinova L, Sherman KE, Butt AA, Falck-Ytter Y, Funderburg NT, et al. CD56(bright) NK IL-7Ralpha Expression Negatively Associates With HCV Level, and IL-7-Induced NK Function is Impaired During HCV and HIV Infections. J Leukoc Biol (2017) 102(1):171-84. doi: 10.1189/ jlb.5A1116-456R

64. Lum JJ, Schnepple DJ, Nie Z, Sanchez-Dardon J, Mbisa GL, Mihowich J, et al. Differential Effects of Interleukin-7 and Interleukin-15 on NK Cell Anti-Human Immunodeficiency Virus Activity. J Virol (2004) 78(11):603342. doi: 10.1128/JVI.78.11.6033-6042.2004

65. Serafini N, Vosshenrich CA, Di Santo JP. Transcriptional Regulation of Innate Lymphoid Cell Fate. Nat Rev Immunol (2015) 15(7):415-28. doi: $10.1038 /$ nri3855

66. Robinette ML, Bando JK, Song W, Ulland TK, Gilfillan S, Colonna M. IL-15 Sustains IL-7R-Independent ILC2 and ILC3 Development. Nat Commun (2017) 8:14601. doi: 10.1038/ncomms14601

67. Moro K, Yamada T, Tanabe M, Takeuchi T, Ikawa T, Kawamoto H, et al. Innate Production of $\mathrm{T}(\mathrm{H}) 2$ Cytokines by Adipose Tissue-Associated C-Kit (+)Sca-1(+) Lymphoid Cells. Nature (2010) 463(7280):540-4. doi: 10.1038/ nature 08636

68. Xu W, Domingues RG, Fonseca-Pereira D, Ferreira M, Ribeiro H, LopezLastra S, et al. NFIL3 Orchestrates the Emergence of Common Helper Innate Lymphoid Cell Precursors. Cell Rep (2015) 10(12):2043-54. doi: 10.1016/ j.celrep.2015.02.057

69. Liu B, Ye B, Zhu X, Huang G, Yang L, Zhu P, et al. IL-7Ralpha Glutamylation and Activation of Transcription Factor Sall3 Promote Group 3 ILC Development. Nat Commun (2017) 8(1):231. doi: 10.1038/ s41467-017-00235-x

70. Yang J, Cornelissen F, Papazian N, Reijmers RM, Llorian M, Cupedo T, et al. IL-7-Dependent Maintenance of ILC3s is Required for Normal Entry of Lymphocytes Into Lymph Nodes. J Exp Med (2018) 215(4):1069-77. doi: 10.1084/jem.20170518

71. Tantawichien T, Young LS, Bermudez LE. Interleukin-7 Induces AntiMycobacterium Avium Activity in Human Monocyte-Derived Macrophages. J Infect Dis (1996) 174(3):574-82. doi: 10.1093/infdis/174.3.574

72. Alderson MR, Tough TW, Ziegler SF, Grabstein KH. Interleukin 7 Induces Cytokine Secretion and Tumoricidal Activity by Human Peripheral Blood Monocytes. J Exp Med (1991) 173(4):923-30. doi: 10.1084/jem.173.4.923

73. McKinlay A, Radford K, Kato M, Field K, Gardiner D, Khalil D, et al. Blood Monocytes, Myeloid Dendritic Cells and the Cytokines Interleukin (IL)-7 and IL-15 Maintain Human CD4+ T Memory Cells With Mixed Helper/ Regulatory Function. Immunology (2007) 120(3):392-403. doi: 10.1111/ j.1365-2567.2006.02515.x

74. Gessner A, Vieth M, Will A, Schroppel K, Rollinghoff M. Interleukin-7 Enhances Antimicrobial Activity Against Leishmania Major in Murine Macrophages. Infect Immun (1993) 61(9):4008-12. doi: 10.1128/iai.61.9.4008-4012.1993
75. Li S, Wang Z, Zhang G, Fu J, Zhang X. Interleukin-7 Promotes LungResident CD14(+) Monocytes Activity in Patients With Lung Squamous Carcinoma. Int Immunopharmacol (2019) 67:202-10. doi: 10.1016/ j.intimp.2018.12.022

76. Standiford TJ, Strieter RM, Allen RM, Burdick MD, Kunkel SL. IL-7 UpRegulates the Expression of IL-8 From Resting and Stimulated Human Blood Monocytes. J Immunol (1992) 149(6):2035-9.

77. Takeuchi S, Katz SI. Use of Interleukin 7 Receptor-Alpha Knockout Donor Cells Demonstrates the Lymphoid Independence of Dendritic Cells. Blood (2006) 107(1):184-6. doi: 10.1182/blood-2005-02-0647

78. Vogt TK, Link A, Perrin J, Finke D, Luther SA. Novel Function for Interleukin-7 in Dendritic Cell Development. Blood (2009) 113(17):39618. doi: 10.1182/blood-2008-08-176321

79. Varas A, Vicente A, Sacedon R, Zapata AG. Interleukin-7 Influences the Development of Thymic Dendritic Cells. Blood (1998) 92(1):93-100. doi: 10.1182/blood.V92.1.93.413a03_93_100

80. Saunders D, Lucas K, Ismaili J, Wu L, Maraskovsky E, Dunn A, et al. Dendritic Cell Development in Culture From Thymic Precursor Cells in the Absence of Granulocyte/Macrophage Colony-Stimulating Factor. J Exp Med (1996) 184(6):2185-96. doi: 10.1084/jem.184.6.2185

81. Marquez C, Trigueros C, Fernandez E, Toribio ML. The Development of T and Non-T Cell Lineages From CD34+ Human Thymic Precursors can be Traced by the Differential Expression of CD44. J Exp Med (1995) 181 (2):475-83. doi: 10.1084/jem.181.2.475

82. Esashi E, Wang YH, Perng O, Qin XF, Liu YJ, Watowich SS. The Signal Transducer STAT5 Inhibits Plasmacytoid Dendritic Cell Development by Suppressing Transcription Factor IRF8. Immunity (2008) 28(4):509-20. doi: 10.1016/j.immuni.2008.02.013

83. Jiang Q, Li WQ, Aiello FB, Mazzucchelli R, Asefa B, Khaled AR, et al. Cell Biology of IL-7, a Key Lymphotrophin. Cytokine Growth Factor Rev (2005) 16(4-5):513-33. doi: 10.1016/j.cytogfr.2005.05.004

84. Fry TJ, Mackall CL. Interleukin-7: From Bench to Clinic. Blood (2002) 99 (11):3892-904. doi: 10.1182/blood.v99.11.3892

85. Moore AJ, In TS, Trotman-Grant A, Yoganathan K, Montpellier B, Guidos CJ, et al. A Key Role for IL-7R in the Generation of Microenvironments Required for Thymic Dendritic Cells. Immunol Cell Biol (2017) 95(10):93342. doi: $10.1038 /$ icb.2017.74

86. Damia G, Komschlies KL, Faltynek CR, Ruscetti FW, Wiltrout RH. Administration of Recombinant Human Interleukin-7 Alters the Frequency and Number of Myeloid Progenitor Cells in the Bone Marrow and Spleen of Mice. Blood (1992) 79(5):1121-9. doi: 10.1182/blood. V79.5.1121.1121

87. Grzegorzewski K, Komschlies KL, Mori M, Kaneda K, Usui N, Faltynek CR, et al. Administration of Recombinant Human Interleukin-7 to Mice Induces the Exportation of Myeloid Progenitor Cells From the Bone Marrow to Peripheral Sites. Blood (1994) 83(2):377-85. doi: 10.1182/blood. V83.2.377.377

88. Jiang Q, Li WQ, Aiello FB, Klarmann KD, Keller JR, Durum SK. Retroviral Transduction of IL-7Ralpha Into IL-7Ralpha-/- Bone Marrow Progenitors: Correction of Lymphoid Deficiency and Induction of Neutrophilia. Gene Ther (2005) 12(24):1761-8. doi: 10.1038/sj.gt.3302558

89. Fossiez F, Djossou O, Chomarat P, Flores-Romo L, Ait-Yahia S, Maat C, et al. T Cell Interleukin-17 Induces Stromal Cells to Produce Proinflammatory and Hematopoietic Cytokines. J Exp Med (1996) 183 (6):2593-603. doi: 10.1084/jem.183.6.2593

90. Forlow SB, Schurr JR, Kolls JK, Bagby GJ, Schwarzenberger PO, Ley K. Increased Granulopoiesis Through Interleukin-17 and Granulocyte ColonyStimulating Factor in Leukocyte Adhesion Molecule-Deficient Mice. Blood (2001) 98(12):3309-14. doi: 10.1182/blood.v98.12.3309

91. Ye P, Rodriguez FH, Kanaly S, Stocking KL, Schurr J, Schwarzenberger P, et al. Requirement of Interleukin 17 Receptor Signaling for Lung CXC Chemokine and Granulocyte Colony-Stimulating Factor Expression, Neutrophil Recruitment, and Host Defense. J Exp Med (2001) 194(4):51927. doi: $10.1084 /$ jem.194.4.519

92. Vellenga E, Esselink MT, Straaten J, Stulp BK, De Wolf JT, Brons R, et al. The Supportive Effects of IL-7 on Eosinophil Progenitors From Human Bone Marrow Cells can be Blocked by Anti-IL-5. J Immunol (1992) 149 (9):2992-5. 
93. Bates ME, Liu LY, Esnault S, Stout BA, Fonkem E, Kung V, et al. Expression of Interleukin-5- and Granulocyte Macrophage-Colony-Stimulating FactorResponsive Genes in Blood and Airway Eosinophils. Am J Respir Cell Mol Biol (2004) 30(5):736-43. doi: 10.1165/rcmb.2003-0234OC

94. Watanabe M, Ueno Y, Yajima T, Okamoto S, Hayashi T, Yamazaki M, et al. Interleukin 7 Transgenic Mice Develop Chronic Colitis With Decreased Interleukin 7 Protein Accumulation in the Colonic Mucosa. J Exp Med (1998) 187(3):389-402. doi: 10.1084/jem.187.3.389

95. Hock H, Dorsch M, Kunzendorf U, Qin Z, Diamantstein T, Blankenstein T. Mechanisms of Rejection Induced by Tumor Cell-Targeted Gene Transfer of Interleukin 2, Interleukin 4, Interleukin 7, Tumor Necrosis Factor, or Interferon Gamma. Proc Natl Acad Sci USA (1993) 90(7):2774-8. doi: $10.1073 /$ pnas.90.7.2774

96. McBride WH, Thacker JD, Comora S, Economou JS, Kelley D, Hogge D, et al. Genetic Modification of a Murine Fibrosarcoma to Produce Interleukin 7 Stimulates Host Cell Infiltration and Tumor Immunity. Cancer Res (1992) 52(14):3931-7.

97. von Freeden-Jeffry U, Davidson N, Wiler R, Fort M, Burdach S, Murray R. IL-7 Deficiency Prevents Development of a Non-T Cell Non-B CellMediated Colitis. J Immunol (1998) 161(10):5673-80.

98. Kelly EA, Koziol-White CJ, Clay KJ, Liu LY, Bates ME, Bertics PJ, et al. Potential Contribution of IL-7 to Allergen-Induced Eosinophilic Airway Inflammation in Asthma. J Immunol (2009) 182(3):1404-10. doi: 10.4049/ jimmunol.182.3.1404

99. Patel A, Patel J, Ikwuagwu J. A Case of Progressive Multifocal Leukoencephalopathy and Idiopathic CD4+ Lymphocytopenia. J Antimicrob Chemother (2010) 65(12):2697-8. doi: 10.1093/jac/dkq359

100. Francois B, Jeannet R, Daix T, Walton AH, Shotwell MS, Unsinger J, et al. Interleukin-7 Restores Lymphocytes in Septic Shock: The IRIS-7 Randomized Clinical Trial. JCI Insight (2018) 3(5):e98960. doi: 10.1172/ jci.insight. 98960

101. Laterre PF, Francois B, Collienne C, Hantson P, Jeannet R, Remy KE, et al. Association of Interleukin 7 Immunotherapy With Lymphocyte Counts Among Patients With Severe Coronavirus Disease 2019 (COVID-19). JAMA Netw Open (2020) 3(7):e2016485. doi: 10.1001/jamanetworkopen.2020.16485

102. Levy Y, Lacabaratz C, Weiss L, Viard JP, Goujard C, Lelievre JD, et al. Enhanced T Cell Recovery in HIV-1-Infected Adults Through IL-7 Treatment. J Clin Invest (2009) 119(4):997-1007. doi: 10.1172/JCI38052
103. Sereti I, Dunham RM, Spritzler J, Aga E, Proschan MA, Medvik K, et al. IL-7 Administration Drives T Cell-Cycle Entry and Expansion in HIV-1 Infection. Blood (2009) 113(25):6304-14. doi: 10.1182/blood-2008-10186601

104. Sereti I, Estes JD, Thompson WL, Morcock DR, Fischl MA, Croughs T, et al. Decreases in Colonic and Systemic Inflammation in Chronic HIV Infection After IL-7 Administration. PloS Pathog (2014) 10(1):e1003890. doi: 10.1371/ journal.ppat.1003890

105. Sportes C, Hakim FT, Memon SA, Zhang H, Chua KS, Brown MR, et al. Administration of rhIL-7 in Humans Increases In Vivo TCR Repertoire Diversity by Preferential Expansion of Naive T Cell Subsets. J Exp Med (2008) 205(7):1701-14. doi: 10.1084/jem.20071681

106. Miller PW, Sharma S, Stolina M, Butterfield LH, Luo J, Lin Y, et al. Intratumoral Administration of Adenoviral Interleukin 7 Gene-Modified Dendritic Cells Augments Specific Antitumor Immunity and Achieves Tumor Eradication. Hum Gene Ther (2000) 11(1):53-65. doi: 10.1089/ 10430340050016157

107. Andersson A, Srivastava MK, Harris-White M, Huang M, Zhu L, Elashoff D, et al. Role of CXCR3 Ligands in IL-7/IL-7R Alpha-Fc-Mediated Antitumor Activity in Lung Cancer. Clin Cancer Res (2011) 17(11):3660-72. doi: 10.1158/1078-0432.CCR-10-3346

Conflict of Interest: The authors declare that the research was conducted in the absence of any commercial or financial relationships that could be construed as a potential conflict of interest.

Publisher's Note: All claims expressed in this article are solely those of the authors and do not necessarily represent those of their affiliated organizations, or those of the publisher, the editors and the reviewers. Any product that may be evaluated in this article, or claim that may be made by its manufacturer, is not guaranteed or endorsed by the publisher.

Copyright (c) 2021 Chen, Tang, Deng, Yang and Tang. This is an open-access article distributed under the terms of the Creative Commons Attribution License (CC BY). The use, distribution or reproduction in other forums is permitted, provided the original author(s) and the copyright owner(s) are credited and that the original publication in this journal is cited, in accordance with accepted academic practice. No use, distribution or reproduction is permitted which does not comply with these terms. 